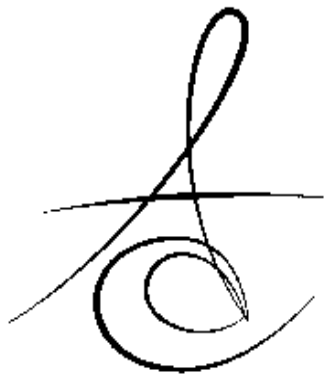

Makale Kodu/Article code: 3080

Makale Gönderilme tarihi: 26.10.2016

Kabul Tarihi: 25.01.2017

\section{GÜLÜMSEME ESTETİĞİNİN DEĞERLENDİRİLMESİ}

EVALUATION OF SMILE ESTHETICS

\author{
Dr.öğr.Üyesi Ekrem ORAL ${ }^{*} \quad$ Prof. Dr. İbrahim YAVUZ** \\ Arş. Gör. Dt. Osman YILDIZ ${ }^{* *}$
}

\section{öz}

Estetik algısı her ne kadar geçmişte sübjektif bir konu olsa da iletişim araçlarının artmasıyla günümüzde hemen hemen tüm kültürlerde ortak olan belli standartlara oturmuştur.

Hastaların artan estetik beklentilerini karşılayabilmek için ideal estetik standartların iyi bilinmesi ve etkili bir biçimde kullanılabilmesi gerekmektedir. Çünkü güncel çalışmalara göre sadece ortodontik açıdan ideal olarak bitirilen tedaviler, hastaların estetik beklentilerini karşlamakta yetersiz kalmaktadırlar.

Derlememizde estetik ve güzellik gibi kavramlar tanımlanacak, gülümsemenin yüz estetiğindeki öneminden, gülümsemenin nasıl değerlendirilmesi gerektiğinden ve literatürde bulunan ve klinisyenlerce genel kabul gören gülümseme estetiğinin belirleyici faktörlerinden bahsedilecektir.

Anahtar kelimeler: Gülümseme, estetik, derleme

\section{GİRİ}

Gülümseme; farklı kültürlerde farklı duygular belirtebilse de genellikle mutluluk ve keyif belirten bir yüz ifadesidir. ${ }^{1}$

Gülümseme, sözsüz sosyal iletişimin en önemli aracı olduğundan kişinin benlik algısında ve sosyal kimliğinde büyük öneme sahiptir. ${ }^{2}$ Güzel bir gülümseme toplumda kabul ettirici rol oynar. Estetik olmayan bir gülümsemeyse kişiyi mutsuz, huysuz, asabi biri olarak gösterebilir.

Estetiğin ve sosyal ilişkilerin öneminin artığı modern toplumlarda dentofasiyal estetiğin iyileştirilmesi sürekli araştırılan bir konu olmuştur. Dentofasiyal estetiğin en önemli ikinci bileşeni olan gülümseme

\section{ABSTRACT}

While in the past perception of esthetic was a subjective topic; with the globalization of the world it become common and had standarts nearly in all cultures.

To meet patient's increasing esthetic expectations clinicians have to learn ideal esthetic standarts and use them effectively. Because recent studies revealed that finishing orthodontic cases with ideal orthodontic occlusal standpoint is not enough to satisfy patient's esthetic expectations.

In this paper; beauty and esthetic concepts will be defined. Importantance of smile in the context of dentofacial esthetics, evaluating smile esthetics and the last previously mentioned in the literature smile esthetic criterias will be discussed.

Keywords: Smile, esthetics, review

\footnotetext{
* Mersin Üniversitesi Diş Hekimliği Fakültesi. Ortodonti AD, Mersin

**Erciyes Üniversitesi Diş Hekimliği Fakültesi. Ortodonti AD, Kayseri
}

estetiği günümüzde dental tedavilerde başlıca öneme sahiptir. . $^{3-5}$

Estetik sonuçlara ulaşabilmek için bazı referans ölçümler takip edilmelidir. Yıllar boyunca bu referans ölçümler uzmanların görüşlerine göre belirlenmiştir fakat estetik, farklı kültürlerde ve kişilerde farklılıklar gösterebilen sübjektif bir kavram olduğundan bu referans ölçümler sorgulanabilirdir. ${ }^{6}$ Bu gerçek, ideal gülümseme estetiğini oluşturacak tedavi protokollerini araştıran klinisyenler için bir engeldir. Kokich ve arkadaşlarının yaptığı çalışma, bazı araştırmacıların dijital görüntüleme teknolojilerinden faydalanarak gülümseme estetiğinde daha bilimsel ve tutarlı referanslar arayan çalışmalarına öncülük etmiştir. ${ }^{7}$ Kokich'in öncülüğünü yaptığı çalışmalarda üzerinde çalıştığı refe- 
ranslar, günümüzde tedavi planlamalarında kendisine yer bulmuş ve tedavileri yönlendiren sabit kurallar haline gelmişlerdir.

$\mathrm{Bu}$ derlemenin amacı hastaların dentofasiyal estetiğin önemli bir bileşeni olan gülümseme estetiğinin önemini ve kurallarını açıklamak, ideal gülümseme estetiğini oluşturacak tedavi protokollerini araştıran klinisyenlere yardımcı olmaktır.

\section{Gülümseme}

Gülümseme; temel olarak ağzın her iki yanındaki zigomatik majör kaslarının kasılması ile gerçekleşen bir yüz ifadesidir. ${ }^{8}$ Zigomatik majör kasına ilave olarak çeşitli kasların kasılmasıyla farklı gülümseme tipleri oluşabilmektedir.

Son dönemde görüntüleme teknolojilerinin de artmasıyla alınan renkli ultrason görüntülerinde gülümsemeye anne karnında başladığımız görülmektedir. ${ }^{9}$

Gülümseme genellikle keyif ve eğlence belirtir fakat nadir de olsa bazı durumlarda endişe, kızgınlık gibi farklı duydular da ifade edebilir. ${ }^{10}$ Farklı kültürler arası yapılan bir çalışmada gülümsemenin tüm kültürlerde bulunan insana özgü evrensel bir ifade olduğu fakat ifade ettiği anlamların kültürler arası farklııılar gösterdiği bulunmuştur. ${ }^{11}$

Mesela; bazı kültürlerde çok fazla gülümseme sığlık ve/veya sahtekarlık olarak algılanmaktadır. Asya'nın bazı bölgelerindeyse gülümseme utanma ve/ veya duygusal buhran ifade eder. Insanlar genelde gülümsemeyi karşılaştıkları kişileri nazikçe selamlamak için kullanabiliyor olsalar da, bazı toplumlardaki bireyler yeni tanıştıkları ve/veya tanımadıkları kişilere gülümsemezler. Örnek olarak bazı eski Sovyetler Birliği ülkelerinde tanımadığınız bir kişiye toplum içinde gülümsemeniz garip hatta şüpheli bulunabilir. ${ }^{12}$ Fakat farklı kültürlerin oluşturduğu bu kadar karışıklığa rağmen hemen hemen her kültürde ve dilde gülümseme ortak ve temel bir ifadedir ve ortak bir anlama sahiptir. ${ }^{13,14}$

\section{Estetik}

Estetik; güzelliğin araştırmasıdır basit bir deyişle çirkinliğin tersidir. Estetik terimi yunanca duygusal algı manasına gelen "aisthētikos" kelimesinden türemiştir. 18.yy'da Alman filozofu Alexander Baumgarten'in (1714 - 1762) 1750 yılında yayınladığı "Aesthetica" adlı kitabından sonra estetik, felsefeden ayrı bir alan haline gelmiştir. ${ }^{15}$ Baumgarten ise estetiği duygusal bilişim bilimi olarak tanımlar.
Estetik objektif ve subjektif olmak üzere iki boyuta sahiptir. Objektif güzellik objenin kendi özellikleriyle ilgilidir, görülebilir güzelliğidir. Subjektif güzellik ise değer yüklü bir niteliktir, değerlendiren kişinin zevkiyle ilişkilidir.

Diş hekimliğinde orofasiyal komplekste yapılan değişikler temel olarak objektif estetiği arttıracak şekilde olmalıdır. Bununla birlikte, hasta fikirleri kültürel ve toplumsal değerler de göz önüne alınarak subjektif güzellik de oluşturularak kozmetik değeri arttırılmalıdır. ${ }^{16}$

\section{Gülümsemenin Değerlendirilmesi Gülümseme Tipleri}

19.yy'da Fransız nörofizyolog Duchenne yüzdeki sinir yollarını araştırmak için bir dizi deney yapmıştır. ${ }^{17}$ Duchenne deneylerinde elektrotları direk olarak yüzünde kalıcı hissizlik olan deneğinin yüz kaslarına uygulayarak yüzünde oluşan değişiklikleri incelemiştir ve çalışmalarını 1862 yılında "The Mechanisms of Human Facial Expression" adlı kitabında yayınlamıştır.

Dr.Paul Ekman, Duchenne'nin çalışmalarından yola çıkarak gülümsemeyi Duchenne'ye de atıfta bulunarak; doğal gülümseme (Duchenne) ve sosyal gülümseme (Non-Duchenne) olmak üzere ikiye ayırmıştır (Resim 1$){ }^{18}$

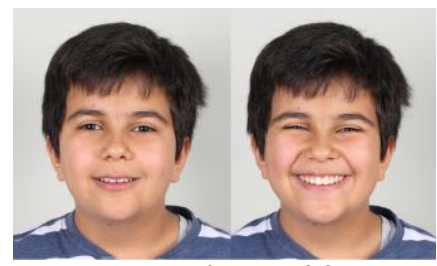

Resim 1. Sirasıyla sosyal (Non- Duchenne) ve spontan (Duchenne) gülümsemeleri.

Sosyal ve doğal gülümseme arasındaki temel fark, sosyal gülümseme duygu durumundan etkilenen bilinçli bir gülümsemedir. Örneğin kötü bir haber almış veya canı sıkkın birinin sosyal gülümsemesinde değişim olacaktır. Spontan gülümseme ise duygulardan bağımsız ve bazen kahkaha şeklinde olabilen doğal bir gülümsemedir. ${ }^{19}$

$\mathrm{Bu}$ iki tip gülümsemede de çalışan ana kas zigomaticus majordür fakat doğal gülümsemede sosyal gülümsemeden farklı olarak göz kenarlarında yer alan ve gözlerin gülerken kısılmasına sebep olan orbicularis oculi kası da çalışır. Ayrıca burun delikleri belirginleşir ve dudaklar maksimum kalkar. ${ }^{20}$ 
5 aylık bebeklerde yapılan bir çalışmada bebeklerin yanına anneleri geldiğinde bebekler orbicularis oculi kasının kasılmasıyla karakterize spontan gülümserken; yanlarına yabancı biri geldiğindeki gülümsemeleri orbicularis oculi kasının kasılmadığı sosyal gülümseme şeklinde olmuştur. ${ }^{21}$

Gülümsemenin Duchenne mi yoksa NonDuchenne mi olduğunu anlamanın en doğru yolu; Ekman ve arkadaşlarının yaptığı bir çalışmaya göre beyindeki elektroensefalografi (EGG) aktivitesi varlığına bağlı olduğu bulunmuştur. ${ }^{22}$

Camara'ya göre estetik planlama spontan gülümsemeye göre planlanmalıdır çünkü sosyal gülümseme gerçeği yansıtmamaktadır, önceden öğrenilmiş bilinçli yapılan bir harekettir. ${ }^{23}$ Fakat hastaların doğru andaki fotoğraflarını yakalamak zordur. Bunun nedeni hastaların doğal gülümsemelerini sağlamak zordur çünkü bir kişiye komik gelen diğerine komik gelmeyebilir.

\section{Kullanılan Kurallar}

3.Gülümsemenin Değerlendirilmesinde Bukkal Koridor

Bukkal koridor (Resim 2) posterior dişlerin bukkal yüzeyleri ile gülümseme esnasında ağız kommisuraları arasında oluşan boşluktur.

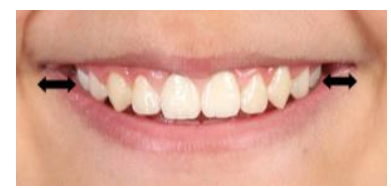

Resim 2. Bukkal koridor.

Bukkal koridor terimi ("negatif boşluk" olarak da adlandırılır) ilk olarak 1950'li yılların sonunda hareketli protez konusunda uzmanlaşmış protez uzmanları tarafından dental litaretüre eklenmiştir. ${ }^{24}$ Protez uzmanı klinisyenler hareketli protezlere diş dizerken doğal görünümü yeniden oluşturmak için protezlerine bukkal koridorları eklediler ve dar, orta, geniş olmak üzere bukkal koridorları üçe ayırdılar.

Zaman içerisinde bukkal koridorlar gülümseme estetiğinin en tartışmalı konusu olmuştur. Literatürde bukkal koridorların gülümseme estetiğine olan etkisiyle ilgili bir fikir birliği yoktur. Bazı makaleler farklı bukkal koridorların gülümseme estetiğini etkilemediğini söylese de bazıları tersini iddia eder.

Sarver'in ${ }^{25} 2001$ yılında yaptığı bir çalışmasında negatif boşlukların bulunmaması en estetikken; Moore ve ark. ${ }^{26}$, Gracco ve ark. ${ }^{27}$, Martin ve ark. ${ }^{28}$, Ioi ve ark. ${ }^{29}$ gibi araştırmacılar yaptıkları çalışmalarında minimal bukkal koridorların, Nascimento ve ark. ${ }^{30}$ orta bukkal koridorları en estetik olduğunu bulmuşlardır.

Hulsey $^{10}$, Kim ve Gianelly ${ }^{31}$, Roden ve ark. ${ }^{32}$, Ritter ve ark. ${ }^{33}$, McNamara ve ark. ${ }^{34}$ gibi araştırmacılar da negatif boşlukların gülümseme estetiğine olumlu veya olumsuz bir etkisi olmadığını bulmuşlardır.

Kokich ve arkadaşlarının 1999 ylında yaptığı bir çalışmaya göreyse diş hekimleri, ortodontistler ve hastalar arasında eşik değeri farklııkları vardır. ${ }^{7}$ Ortodontistler için estetik olmayan göz tırmalayan bir unsur hastaların hatta diş hekimlerinin bile dikkatini çekmeyebilir. Sonuç olarak Kokich'e göre bukkal koridorların varlığı şiddetli olmadıkça olumsuz bir etkiye sahip değildir.

\section{Keser Görünümü Miktarı}

Dudaklar gülüşün çerçevesi olduğundan, estetik alanı belirlerler ve kassal yapılar olduklarından istirahat ve fonksiyon hali olmak üzere ayrı ayrı değerlendirilmelidirler.

İstirahat veya statik pozisyon: Dudakların hafif ayrık, dişlerin oklüzyon dışı ve perioral kasların göreceli istirahatte olduğu durumdur. ${ }^{35}$

Hastaya 'Emma' kelimesi söylettirilerek kolayca

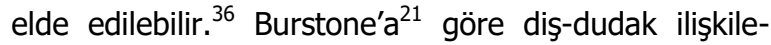
rinin belirlenmesinde istirahat pozisyonunun kullanımı gülümsemeden daha uygundur, çünkü istirahatteki dudak pozisyonu tekrarlanabilirdir, ancak hastanın kayıt sırasındaki sosyal gülümsemesi her seansta farklılık gösterebilir.

İstirahat durumunda üst keser dişlerin ortalama olarak 2-4 mm insizal görünüme sahip olması istenir. ${ }^{37}$ Fakat bu genel bir ifadedir. İstirahatteki keser görünümünü cinsiyet ve yaş faktörlerine göre değerlendirildiğinde; erkeklerde maksiller kesiciler ortalama $1,91 \mathrm{~mm}$ görünmelidir bayanlarda ise $3,40 \mathrm{~mm}$, yani kadınlar ve erkekler arasında neredeyse iki kat bir fark vardır. ${ }^{38}$

Yaşlanmayla beraber fasiyal kasların tonusunda kayıp meydana gelir üst dudağın elastikiyeti artar ve istirahat durumundaki maksiller keser görünümü de giderek azalır. Yaşlanma ile beraber gerçekleşen bu düzenli azalmaya, artan mandibular kesici görünümü de eşlik eder. ${ }^{39}$

Ayrıca keser görünümü maloklüzyona göre de değişim gösterir Sınıf III maloklüzyona sahip bireyler-

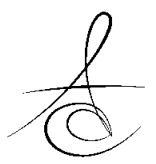


de artmış alt keser görünümü görülürken; tersi olarak Sinıf II maloklüzyona ve prokline üst keserlere sahip hastalarda artmış üst keser görünümü görülür ${ }^{21}$.

Dudakların fonksiyon halindeki değerlendirmesi temel olarak gülümseme değerlendirilmesiyle yapilır. $\mathrm{Bu}$ durumdaki üst dudak-maksiller keser ilişkisini tanımlamak için dudak çizgisi (gülümseme hattı) terimi kullanilır.

\section{Dudak Çizgisi (Gülümseme hattı)}

Estetik alandaki diş ve dişeti görünüm miktarı gülümseme estetiğinde büyük öneme sahiptir. Tjan ve arkadaşlarına ${ }^{39}$ göre gülümsemedeki diş ve dişeti görünümü miktarı gülümseme hattı terimiyle ifade edilir ve yüksek, orta ve düşük olarak tanımlanır(Resim 3).

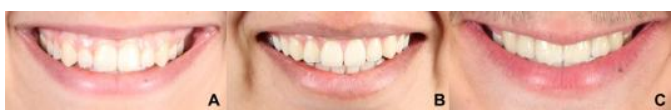

Resim 3. A)Yüksek dudak çizgisi B)Orta dudak çizgisi C)Düşük dudak çizgisi.

A) Yüksek dudak çizgisi: Üst keser görünümü $\% 100$ 'dür ve gingival görünüm mevcuttur (Resim 3A).

B) Orta dudak çizgisi: Üst keser kron görünümü \%75-100 arasındadır. Dişeti görünümü yoktur (Resim 3B).

C) Düşük dudak çizgisi: Üst dudağın üst keserleri örtmesine bağlı olarak üst keser görünümü \%75'den daha azdır (Resim 3C).

Literatüre göre ${ }^{7,40,41}$ en estetik dudak çizgisi 3 mm'den daha az gingival görünüme sahip yüksek dudak çizgisidir. Gülümseme çizgisi de dudak tonusu azalmasına bağlı yaşlandıkça alçalır.

Üst dudağın maksimum yukarı kalktığı bir gülümsemede kadınların dişeti görünümü erkeklerden ortalama $1.5 \mathrm{~mm}$ daha fazladır. ${ }^{42}$ Rigsbee'ye göre kadınlar için ideal gülümsemedeki maksimum dişeti görünümü $2 \mathrm{~mm}$ 'dir. $^{43}$ Allen ve arkadaşlarının çalışmasındaysa cinsiyet ayrımı yapılmadan bu değerin $3 \mathrm{~mm}$ olduğu bulunmuştur. ${ }^{44}$

Fakat bu değerlendirmeler yaş ve cinsiyete bağlı olduğu için kesin bir sayı vermek mümkün değildir ama genel olarak gülümsemede $3 \mathrm{~mm}$ 'den fazla dişeti görünümü gummy smile (dişeti gülümsemesi) olarak tanımlanabilir. ${ }^{45}$

Gummy smile tüm dişlerde olabileceği gibi sadece posterior bölgede tek veya çift taraflı olarak da bulunabilir.
Gummy smile sınıflaması tam bir gülümsemede dişeti görünüm miktarının maksiller santral keser yüksekliğinin yüzdesine göre hesaplanır. Maksiller santral keserlerin yüksekliğinin \%1-25'i arasında dişeti görünümü olanlar hafif, $\% 25-50$ arası olanlar orta, \%50-100 arası olanlar ileri, $\% 100$ 'den fazla olanlar şiddetli dişeti gülümsemesine sahip kabul edilirler.

\section{Gülümseme Arkı (Gülümseme Kurvatürü)}

Gülümseme arkı; gülümseme esnasında üst çenedeki keser dişlerin insizallerinden geçen çizginin alt dudak kurvatürü ile olan ilişkisidir. Estetik gülümsemede maksiller anterior dişlerin insizal uçları konveks bir kurvatür oluşturmalı ve bu kurvatür alt dudak kurvatürüyle uyumlu olmalıdır.

Anterosüperior kanin-kanin arası veya birinci premolarlar arası bölgeye estetik alan denir ve estetik alanda maksiller santral keserler kilit rol oynar ve bu durum "santral keserlerin egemenliği" terimiyle karakterize edilir.

İdeal bir gülümsemede maksiller lateral keserlerin alt dudaktan ideal uzaklığı 0.5-1.5 mm olmalıdır fakat santral keserler ve kaninler alt dudak çizgisi ile daha yakın ilişkide olmalıır (belli belirsiz bir temas istenir). Bu ilişkiyi sağlayabilmek için; kadınlarda üst lateraller ile santraller arasındaki basamak 1-1,5 mm olmalıdır. Erkeklerde 0,5-1 mm arasında olmalıdır.

Konveks, düz, ters olmak üzere 3 çeşit (Resim 4) gülümseme arkı tanımlanmışıı. ${ }^{46}$ En estetik olan gülümseme arkı konvekstir bunu düz takip eder en az estetik olan ters gülümseme arkıdır.

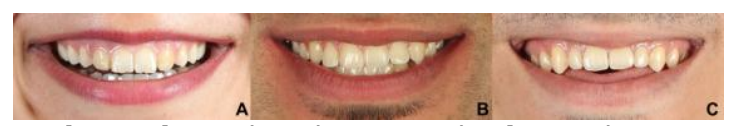

Resim 4. A)Konveks gülümseme arkı B)Düz gülümseme arkı C)Ters gülümseme arkı

Anterosüperior dişlerin insizal kenarların daha kurvatürlü olması kişinin gülümsemesini daha genç gösterir tersi olarak da ters gülümseme arkları daha yaşlı gösterir.

Hastanın gülümsemesi değerlendirilirken maksiller düzlem ve baş açılanmasına dikkat edilmelidir. Hastanın başını öne doğru eğmesi yani hastanın başının saat yönünde rotasyon yapması keser görünümünün artmasına sebep olur. Bunun sonucu olarak konveks gülümseme arkı görünümü oluşur. Tersi olursa da düz veya ters gülümseme arkı görünümü oluşur. ${ }^{20}$ İdeal kayıt için, hastanın oklüzal düzlemi, sağ ve sol olmak 
üzere her iki tragus noktasının ortasını burun tabanı ile birleştiren Camper düzlemine paralel olmalıdır. ${ }^{21}$

\section{Orta Hat ve Dişlerin Angulasyonu}

Bukkal koridorlara benzer olarak orta hat sapmasının gülümseme estetiğindeki rolü tartışmalıdır. Hatta bazı kaynaklara göre dental literatürdeki bütün estetik parametrelere göre dental orta çizgi anomalileri en az dikkat edilen parametredir.

Ortodonti açısından mandibular ve maksiller orta çizgilerin her ikisinin de fasiyal orta hatla çakışması önemli olsa da estetik bakış açısından alt orta çizgi daha az önemlidir. Bunun sebebi alt keser dişlerin daha dar, daha küçük ve aynı boyutlarda olmalarından ve genellikle dudak ve diğer yumuşak dokular tarafından maskelenmeleridir. ${ }^{37}$

Maksiller dental orta çizgiyle fasiyal orta çizgi popülasyonun yüzde 70 'inde çakışmaktadır. ${ }^{37}$ Populasyonun dörtte üçünde maksiller ve mandibular orta çizgiler çakışmaz. ${ }^{47}$

Çoğu hastanın burnu ve çenesi merkezden sapma gösterdiği için orta hattı belirlemede önemleri düşüktür. Fasiyal orta hattı belirlemede kullanılan iki önemli anatomik nokta vardır bunlar nasion ve filtrum çukurunun orta tabanı olan "cupid's bow" noktalarıdır bu noktalardan geçen çizgi fasiyal orta hattır ve ideal estetik için dental orta hatla kesişmelidir.

Pinho ve arkadaşları ${ }^{48}$ yaptıkları bir çalışmada $2 \mathrm{~mm}$ 'ye kadar olan dental orta hat kaymalarının ortodontistler tarafından büyük ölçüde algılandığını bulmuşlardır. Prostodontistler $3 \mathrm{~mm}$ ve üzerindeki değişiklikleri algılarken meslek dışı insanlar $4 \mathrm{~mm}$ ve üzerini algılamışlardır.

Orta hat sapmaları meslek dışı insanlar tarafından zorla fark edilebilirken estetik bölgedeki diş angulasyonlarındaki değişimler kişinin gülümsemesinde daha fazla öneme sahiptir. Literatüre göre anterior dişlerin cephe görünümünde $2 \mathrm{~mm}$ 'den fazla olan angulasyon bozuklukları meslek dışı kişiler tarafından estetik dışı olarak algılanır. ${ }^{49} \mathrm{Bu}$ nedenle bu bozukluk tedavi edilmelidir. Angular bozuklukların tedavisi klasik estetik literatürüne göre tedavi edilmelidir. Santral keserlerin insizal kenar çizgisi interpupiller çizgiye paralel olmalıdır. $10^{\circ}$ den büyük eğim meslek dışı insanlar tarafından kabul edilemez bulunurken bu ortodontistler için $6^{\circ}$ derecedir. ${ }^{50}$

Angulasyon, dental orta hattan daha önemli bir faktör olduğundan fasiyal orta hatla dental orta hattın paralel olması çakışmasından daha önemlidir. Orta hat asimetrileri genellikle posterior oklüzyon ile ilgilidir ve maloklüzyon düzeltildiğinde orta hatlar genellikle çakışır. ${ }^{51}$

\section{Gülümseme Simetrisi}

Gülümseme simetrisi temel olarak gülümseme esnasındaki dudak köşelerinin birbirleriyle olan uyumlarına ve kommissural düzlem ile pupillar düzlemin paralelliğine göre belirlenir. ${ }^{21}$

Transvers dental asimetri değerlendirmelerinde cephe gülümseme fotoğrafları kullanılır. Aşırı derecedeki gülümseme asimetrisinin temel sebebi yüzün bir tarafındaki kas tonusu yetersizliğidir. Tedavisi için hastalara myofonksiyonel egzersizler önerilir.

Simetri intiyacı orta hatta yaklaştıkça artmaktadır orta hattan uzakta olan dişlerin asimetrisi daha kabul edilebilirdir. ${ }^{52,53}$

\section{Maksiller Santral Keserlerin Oranı ve Simetrisi}

Diş boyutu ve oranları hastalar arasında büyük bir çeşitliliğe sahiptir ve hatta yaşam boyunca meydana gelen fizyolojik veya patolojik yıpranmalar sonucu bu oran aynı hastada bile zamanla farklılık gösterebilir. Maksiller santral keserlerin ideal genişlik/ uzunluk oranı (W/H) \%75-85 arasıdır. ${ }^{54}$

Sterrett ve arkadaşlarının ${ }^{55}$ çalışmalarına göre erkeklerin diş boyutları kadınlarınkinden daha büyüktür. Değerlerin kadınlar için daha çok \%75'e yakın olması istenir erkekler de ise $\% 85^{\prime}$ e yakın değerler de kabul edilebilirdir. 0.6'dan küçük oran dar ve uzun, 0.85 'den büyük bir oran kısa ve geniş bir dişi tanımlar. Ortalama olarak santral keser dişlerin uzunluğu 9.5$10.2 \mathrm{~mm}$ arasında genişliği ise 8.1 ve $8.6 \mathrm{~mm}$ arasında değişir.Yaşlanmaya bağlı olarak gingivanın apikale migrasyonu gerçekleşir ve kron boyu uzar.

W/H oranı bozuk olan vakalarda önce hangi maksiller santral dişin ideal orana sahip olduğuna bakılır. Bunun yapılmasının nedeni referans olarak kullanılacak dişi seçmektir. Eğer iki dişin birden düzeltilmesi gerekiyorsa referans olarak yükseklikleri kullanılır. Diğer bir deyişle estetik santral keserlerin kron yükseklikleri genelde 9,5 ila $11 \mathrm{~mm}$ arasında olur. ${ }^{56}$

\section{Anterosüperior Dişler Arasındaki Oran}

Diş hekimliğinde en çok kabul gören oran Levin'in 1978'de diş hekimliğine uyarladığı altın orandır. ${ }^{57}$ Yazara göre anterosüperior dişlerin cephe görünümünde genişlikleri arasında ideal bir oran vardır. Bu

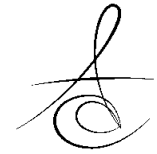


oran maksiller lateral keserin cepheden görülen genişliği, santral keserin cepheden görülen genişliğinin $\% 62$ 'si olmalı kaninin görünen genişligi ise lateralin genişliğinin \%62'si olmalıdır (Resim 5). Dişlenmeye farklı açılardan bakıldığında farklı diş boyutları oluşacağından hasta tam karşıdan değerlendirilmelidir.

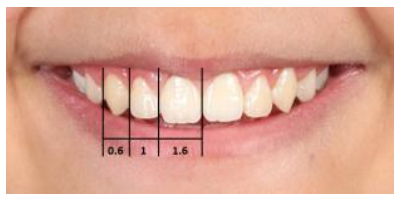

Resim 5. Altın orana göre dizilmiş anterosüperior dişler.

Altın oran binalar, resimler gibi cansız objelerde ve hatta yaşayan organizmalarla güzel bir uyum sağlasa da dişlerle ilişkisi ideali yansıtmamaktadır. Yapılan çalışmaların çoğu insanların anterior dişlerinin altın orana uymadığını göstermiştir. Altın orana katı bağllık ve uygulama sonucu hastaların maksiller arklarında gereksiz bir daralma oluştuğu görülmüştür. ${ }^{58,59}$

\section{Anterosüperior Boşlukların Mevcudiyeti}

Estetik alandaki diastemaların mevcudiyetinin estetik açıdan değerlendirilmesi literatürde geniş olarak tartışımışır. Literatüre göre $2 \mathrm{~mm}$ 'den fazla olmayan küçük diastemalar meslek dışı kişiler tarafından fark edilmezler. ${ }^{51}$ Orta hat diastemalarının gülümseme estetiğine olan olumsuz etkisi düşünüldüğünde bu iddia gerçeklikten uzaktır ve sorgulanmalıdır.

Bu soruyu cevap arayan Machado ve arkadaşlarının ${ }^{60} 2013$ yılında yaptıkları çalışmanın sonuçlarına göre diastemanın büyümesi ve orta hatta ne kadar yakın olması estetiği o derecede bozmaktadır. Sadece maksiller laterallerin distalinde olan ve $0.5 \mathrm{~mm}$ olan boşluklar fark edilmemiştir. Estetik yüksek derecede subjektif olmasına rağmen orta hat diastemaları mutlaka ortodontik veya multidisipliner olarak kapatılmalıdır ve eğer ortodontik tedavi sonrası mutlaka boşluk kalması gerekiyorsa laterallerin distallerindeki bölge en iyi tercihtir.

\section{İnsizal Embraşürler}

İnsizal embraşürler maksiller anterior dişlerin insizallerindeki ayrıma yani uçlarının birbirinden uzaklaşması sonucu dişler arasında oluşan boşluklardır. Embrajür boşlukları yaklaşık olarak ters bir "V" şeklindedir (Resim 6) ve dişler arasındaki bu boşluk santral keserden arka grup dişlere doğru gittikçe boyut ve hacim olarak artar. ${ }^{21}$

Foulger ve arkadaşları ${ }^{61}$ diş hekimleri, hastalar ve dental teknisyenler arasında yaptıkları bir çalışmada embrajür boşlukların yetersizliğinin gülme estetiğini önemli ölçüde olumsuz etkilediğini gösterdiler.

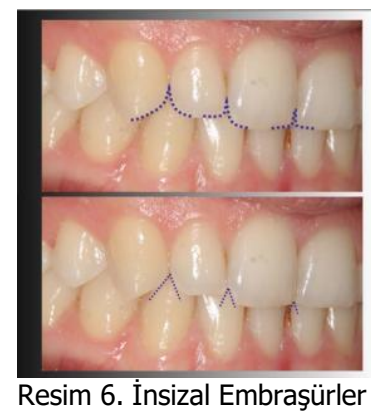

\section{Konnektörler}

Konnektör alanı komşu anterior dişlerin temas noktasından dişeti papiline kadar olan kısımdır.

İdeal gülümsemede anterior dişler arasında 5040-30 kuralı olarak adlandırılan ilişki (Resim 7) olmalıdır. Santral keserler arasındaki ideal konnektör aralığı kron boyutunun \%50'si kadar, maksiller santral ve lateraller arası olan konnektör aralığı santral keserin \%40' kadar olmalıdır, lateral keser ve kaninler arası konnektör aralığı santral keserin kron boyutunun $\% 30^{\prime} u$ kadar olmalıdır. ${ }^{21}$

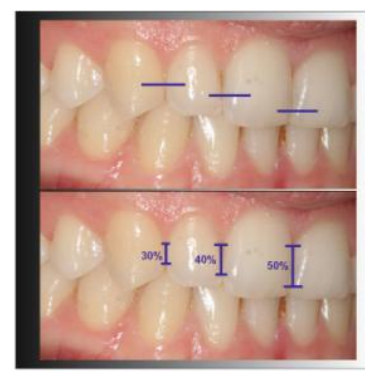

Resim 7. İdeal konnektör oranı (50-40-30 kuralı)

\section{Dişeti Tasarımı}

Dişeti tasarımı da estetik tedaviye dahil edilmelidir. "pembe estetik" ve "kırmızı estetik" terimleri gülümsemedeki ideal dişeti konturunu tanımlamada kullanılmaktadır.

Literatüre göre ideal dişeti estetiği için kaninlerin gingival marjinlerinin santrallerin gingival marjinleri ile aynı seviyede olması ve laterallerin marjinlerinin de bu seviyeden hafif aşağıda olması gerekir. ${ }^{40}$

Çok kullanılan başka bir estetik parametre de gingival konturun en apikal noktası olan gingival zenith

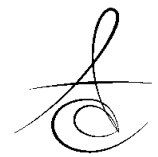


(apexdir). Estetik alanda yapılan cephe analizlerine göre gingival apeksler kronun merkezinde veya hafif distalinde yer alır.

Literatüre göre, santral keserde 1,5-2 mm'den daha az olan zenith asimetrileri meslek dışı kişiler tarafından algılanmazlar., ${ }^{7,49}$

Correa ve arkadaşlarının ${ }^{62}$ yaptığı bir çalışmaya da göre kaninlerdeki 1.5-2 mm'ye kadar olan gingival asimetriler meslek dışı kişiler tarafından algılanmamaktadırlar. Bu verilere göre bir kez daha beyaz estetiğin pembe estetikten daha önemli olduğu bulunmuştur.

Overerüpsiyona uğrayan dişin gingival hattı da dişle beraber taşınır ve bu durum gingival seviyenin insizale taşınmasına sebep olur.

Kaninin lateral yapılması durumunda eğer kaninin gingival seviyesi santralinkine göre daha gingivaldeyse kanin ekstrüze edilip en azından gingival seviyeler eşit hale getirilmelidir.

\section{Siyah Üçgenler (Karanlık Üçgenler)}

Sağlıklı periodonsiyumda interdental papilla komşu dişlerin kontak noktaları boyunca uzanan boşluğu doldurmalıdır. Periodontal hastalık sonrası, diş kaybı veya kötü restorasyon sonucu interdental papilla kaybedilebilir ve sonucunda da "karanlık üçgenler" adı verilen istenmeyen boşluklar oluşur.

Kontak noktaları ile interproksimal kemik kreti arasındaki mesafe $5 \mathrm{~mm}$ veya daha az ise gingival embrajürleri papil tam olarak doldurur. Bu mesafenin 5 mm'nin üzerine arttığı her $1 \mathrm{~mm}$ için boşluğun papil ile tam dolma şansı yüzde 50 oranında kademeli olarak azalır.

Klinisyen özellikle yüksek gülümseme hattına sahip hastalarda interdental papilla eksikliğinin dental estetik üzerinde ne kadar fazla yıkıcı etkisinin olacağının farkında olmalıdır. Pembe estetiği optimize etmek için estetik periodontal cerrahi, ortodonti veya sabit protetik yaklaşımlar tek tek veya kombine olarak kullanılabilir.

\section{SONUÇLAR}

Estetik algısı her ne kadar geçmişte subjektif bir konu olsa da günümüzde artık belli standartlara oturmuştur. Hastaların artan estetik beklentilerini karşılayabilmek için bu standartların iyi bilinmesi ve etkili bir biçimde kullanılabilmesi gerekmektedir. Çünkü yapılan son çalışmalara göre sadece ortodontik açıdan ideal olarak bitirilen tedaviler hastaların estetik beklentilerini karşılamakta yetersiz kalmaktadırlar.

Ekrem ORAL: ORCID ID: 0000-0002-3337-6261

İbrahim YAVUZ: ORCID ID: 0000-0001-5760-4858

Osman YILDIZ: ORCID ID: 0000-0003-0600-4021

\section{KAYNAKLAR}

1. Pessa JE, Zadoo VP, Garza PA, Adrian EK, Dewitt AI, Garza JR. Double or bifid zygomaticus majör muscle: Anatomy, incidence, and clinical correlation. Clin Anat 1998;11:310-3.

2. Tarantili VV, Halazonetis DJ, Spyropoulos MN. The spontaneous smile in dynamic motion. Am J Orthod Dentofacial Orthop 2005;128:8-15.

3. Goldstein RE. Study of need for esthetics in dentistry. J Prosthet Dent 1969;21:589-98.

4. Gochman DS. The measurement and development of dentally relevant motives. J Public Health Dent 1975;35:160-4.

5. Mandalı G, Biçer A.Z.Y, Bulut Z, Konakçı B. Anterior bölgede estetik yaklaşımlar: olgu sunumu. Atatürk Üniv Diş Hek Fak Derg 2011;21:80-5.

6. Van der Geld P, Oosterveld P, Heck GV, KuijpersJagtman AM. Smile attractiveness: self-perception and Influence on Personality. Angle Orthod 2007;77:759-75.

7. Kokich VO, Kiyak HA, Shapiro PA. Comparing the perception of dentists and lay people to altered dental esthetics. J EsthetDent. 1999;11:311-24.

8. Waller BM, Cray JJ, Burrows AM. Selection for Universal Facial Emotion. Emotion 2008;8:435-9.

9. Kawakami F, Yanaihara T. Smiles in the fetal period. Infant Behavior and Development 2012;35:466-71.

10. Hulsey CM. An esthetic evaluation of lip-teeth relationships present in the smile. Am J Orthod Dentofacial Orthop 1970;57:132-44.

11. Izard CE. The Face of Emotion. 1 ed. New York 1971.

12. Ikeda J, Tidwell C. Cultural Differences in Nonverbal Communication. 1 ed. New York; Vermont Department of Health: 2009.

13. Young S. Human facial expressions. 1 ed. Cambridge; The Cambridge Encyclopedia of Human Evolution: 1992. p. 164-5.

14. Kingdon J. Facial patterns as signals and masks. 1 ed. Cambridge; The Cambridge Encyclopedia of Human Evolution: 1992. p. 161-5. 
15. Baumgarten AG. Aesthetica (1750). 1 ed. Paris; L'herne: 1989.

16. Zachrisson BU. Esthetic factors involved in anterior tooth display and the smile: vertical dimension. J Clin Orthod 1998;32:432-45.

17. Duchenne de Boulogne GB. The Mechanism of Human Facial Expression (1862). 1 ed. Paris: Jules Renard. Ed. and trans. Cuthbertson RA. Cambridge; Cambridge University Press: 1990.

18. Ekman P. Facial expression of emotion: new findings, new questions. Psychol Sci 1992;3:34-8.

19. Ackerman MB, Ackerman JL. Smile Analysis and Design in the Digital Era. J Clin Orthod 2002;36:221-36.

20. Burstone CJ, Charles J, Burstone MS. Part 1 facial esthetics. Interview by Ravindra Nanda. J Clin Orthod 2007;41:79-87.

21. Naini FB. Facial aesthetics: concepts and clinical diagnosis. 1 ed. New Jersey; Wiley-Blackwell: 2011.

22. Ekman P, Davidson RJ. Voluntary smiling changes regional brain activity. Psychol Sci 1993;4:342-5.

23. Camara CA. Aesthetics in Orthodontics: Six horizontal smile lines. Dental Press J Orthod. 2010;15:118-31.

24. Prasad V, Tandon P, Sharma VP, Singh GK, Maurya RP, Chugh V. Photographical evaluation of smile esthetics after extraction orthodontic treatment. Journal of Orthodontic Research 2015;3:49-56.

25. Sarver DM. The importance of incisor positioning in the esthetic smile: the smile arc. Am J Orthod Dentofacial Orthop 2001;120:98-111.

26. Moore T, Southard KA,Casko JS, Qian F, Southard TE. Buccal corridors and smile esthetics. Am J Orthod Dentofacial Orthop 2005;127:208-13.

27. Gracco A, Cozzani M, D’Elia L, Manfrini M, Peverada C, SicilianiG. The smile buccal corridors: aesthetic value for dentists and laypersons. Progress in Orthodontics 2005;7:56-65.

28. Martin A, Buschang P, Boley J, Taylor R, McKinney T. The impact of buccal corridors on smile attractiveness. Eur J Orthod 2007;29:530-7.

29. Ioi H, Nakata S, Counts AL. Effects of buccal corridors on smile esthetics in Japanese. Angle Orthod 2009;79:628-33.

30. Nascimento DC, Santos ER, Machado AW, Bittencourt MAV. Influence of buccal corridor dimension on smile esthetics. Dental Press J
Orthod. 2012;17:145-50.

31. Kim E, Gianelly AA. Extraction vs nonextraction: arch widths and smile esthetics. Angle Orthod 2003;73:354-8.

32. Roden JD, Gallerano R, English J. The effects of buccal corridor spaces and arch form on smile esthetics. Am J Orthod Dentofacial Orthop 2005;127:343-50.

33. Ritter DE, Gandini LG, Pinto AS, Locks A. Esthetic influence of negative space in the buccal corridor during smiling. Angle Orthod 2006;76:198-203.

34. McNamara L, McNamara JA, Ackerman MB, Baccetti T. Hard- and soft-tissue contributions to the esthetics of the posed smile in growing patients seeking orthodontic treatment. Am J Orthod Dentofacial Orthop 2008;133:491-9.

35. Ahmad I. Anterior dental aesthetics: Dentofacial perspective. Br Dent J 2005;199:81-8.

36. Bhat VS, Gopinathan M. Reliability of determining vertical dimension of occlusion in complete dentures: A clinical study. JIPS 2006;6:38-42.

37. Sharma PK, Sharma P. Dental Smile Esthetics: The Assessment and Creation of the Ideal Smile. Seminars in Orthodontics 2012;18:193-201.

38. Vig RG, Brundo GC. The kinetics of anterior tooth display. J Prosthet Dent 1978;39:502-4.

39. Tjan AH, Miller GD, Josephine GP. Some esthetic factors in a smile. J Prosthet Dent 1984;51:24-8.

40. Machado AW. 10 commandments of smile esthetics. Dental Press J Orthod 2014;19:136-57.

41. Suzuki L, Machado AW, Bittencourt MAV. An evaluation of the influence of gingival display level in the smile esthetics. Dental Press J Orthod. 2011;16:37-9.

42. Peck S, Peck L, Kataja M. Some vertical lineaments of lipposition. Am J Orthod Dentofacial Orthop 1992;101:519-24.

43. Rigsbee $\mathrm{OH} 3 r d$, Sperry TP, BeGole EA. The influence of facial animation on smile characteristics. Int J Adult Orthod Orthog Surg 1988;3:233-9.

44. Allen EP. Use of mucogingival surgical procedures to enhance esthetics. Dent Clin North Am 1988;32:307-30.

45. Sabri R. The Eight Components of a Balanced Smile. J Clin Orthod 2005;39:155-67.

46. Machado AW, McComb R, Moon W, Gandini LG. Influence of the vertical position of maxillary

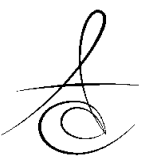


central incisors on the perception of smile esthetics among orthodontists and laypersons. J Esthetic Rest Dent 2013;25:392-401.

47. Miller EL, Bodden WR, Jamison HC. A study of the relationship of the dental midline to the facial median line. J Prosthet Dent 1979:41:657-60.

48. Pinho S, Ciriaco C, Faber J, Lenza MA. Impact of dental asymmetries on the perception of smile esthetics. Am J Orthod Dentofacial Orthop 2007;132:748-53.

49. Kokich VO, Kokich VG, Kiyak HA. Perceptions of dental professionals and laypersons to altered dental esthetics: asymmetric and symmetric situations. Am J Orthod Dentofacial Orthop 2006;13:141-51.

50. Thomas JL, Hayes C, Zawaideh S. The effect of axial midline angulation on dental esthetics. Angle Orthod 2003:73:359-64.

51. Morley J, Eubank J. Macroesthetic elements of smile design. J Am Dent Assoc 2001;132:39-45.

52. Machado AW, Moon W, Gandini LG. Influence of maxillary incisor edge asymmetries on the perception of smile esthetics among orthodontists and laypersons. Am J Orthod Dentofacial Orthop 2013;143:658-64.

53. Chiche G, Pinault A. Esthetics of anterior fixed prosthodontics. 1 ed. Chicago; Quintessence: 1994.

54. Wolfart S, Thormann H, Freitag S, Kern M. Assessment of dental appearance following changes in incisor proportions. Eur J Oral Sci 2005; 113:159-65.

55. Sterrett JD , Oliver T, Robinson F , Fortson W , Knaak B , Russell CM. Width/length ratios of normal clinical crowns of the maxillary anterior dentition in man. J Clin Periodontol 1999;26:153-7.

56. Rufenacht CR. Fundamentals of esthetics. 1 ed. Chicago; Quintessence: 1990.

57. Levin EI. Dental esthetics and the golden proportion. J Prosthet Dent 1978;40:244-52.

58. Bukhary SMN, Gill DS, Tredwin CJ, Moles DR. The influence of varying maxillary lateral incisor dimensions on perceived smile aesthetics. $\mathrm{Br}$ Dent J. 2007;22:687-93.

59. Preston JD. The golden proportion revisted. J Esthet Dent. 1993;5:247-51.
60. Machado AW, Moon W, Campos E, Gandini LG. Influence of spacing in the upper lateral incisor area on the perception of smile esthetics among orthodontists and laypersons. Journal of the World Federation of Orthodontists 2013;25:169-74.

61. Foulger TE, Tredwin CJ, Gill DS, Moles DR. The influence of varying maxillary incisal edge embrasure space and interproximal contact area dimensions on perceived smile aesthetics. British dental journal 2010;209:4-5.

62. Correa BD, Bittencourt MAV, Machado AW. Influence of maxillary canine gingival margin asymmetries on the perception of smile esthetics among orthodontists and laypersons. Am J Orthod Dentofacial Orthop 2014;145:55-63.

\section{Yazışma Adresi}

Dr.Öğr.Üyesi Ekrem ORAL

Mersin Üniversitesi Diş Hekimliği Fakültesi

Ortodonti Anabilim Dalı Yenişehir/Mersin

e-mail: dt.ekremoral@gmail.com 